\title{
The effect of $\mathrm{H}_{2} \mathrm{O}$ adsorption on cloud drop activation of insoluble particles: a theoretical framework
}

\author{
R. Sorjamaa ${ }^{1}$ and A. Laaksonen ${ }^{1,2}$ \\ ${ }^{1}$ University of Kuopio, Department of Physics, P.O. Box 1627, 70211 Kuopio, Finland \\ ${ }^{2}$ Finnish Meteorological Institute, P.O. Box 503, 00101 Helsinki, Finland
}

Received: 22 February 2007 - Published in Atmos. Chem. Phys. Discuss.: 11 June 2007

Revised: 17 September 2007 - Accepted: 30 November 2007 - Published: 19 December 2007

\begin{abstract}
Cloud droplet activation of wettable insoluble compounds has been studied theoretically by assuming that droplet growth happens through multilayer adsorption. The idea is to include an adsorption isotherm in Köhler theory instead of the solute term. This makes it possible to describe the equilibrium growth of insoluble particles and to find out their critical saturation ratios. The critical saturation ratios calculated in this way are comparable to those of completely soluble particles at certain ranges of adsorption isotherm parameter values. The results indicate that adsorption could cause wettable insoluble compounds to activate in atmospheric conditions. However, more data on the adsorption parameters for wettable organic substances is needed to confirm this conclusion.
\end{abstract}

\section{Introduction}

The uncertainty related to the magnitude of the indirect effects of atmospheric aerosols on cloud properties is large and causes problems when evaluating the climate forcing caused by anthropogenic aerosols (IPCC, 2001). This is largely due to insufficient information about atmospheric aerosol compounds and their ability to act as cloud condensation nuclei $(\mathrm{CCN})$ and to form cloud droplets. While the effect of water-soluble inorganic compounds on cloud formation is well characterized, the effect of organics has remained somewhat unclear even though intensive studies have been carried out during the recent years. The reason for this is the enormous number of different organic compounds with different chemical and physical properties present in the atmosphere.

Several laboratory studies have been carried out in order to find out the CCN efficiencies of different single-component organic aerosols (Cruz and Pandis, 1997; Corrigan and No-

Correspondence to: R. Sorjamaa

(riikka.sorjamaa@uku.fi) vakov, 1999; Hegg et al., 2001; Raymond and Pandis, 2002; Kumar et al., 2003; VanReken et al., 2005; Huff Hartz et al., 2006) while also mixtures of inorganic and organic compounds have been studied (Cruz and Pandis, 1998; Hegg et al., 2001; Bilde and Svenningsson, 2004). As the knowledge of the properties of organic compounds has increased also theoretical steps forward have been taken. The traditional Köhler theory that describes the equilibrium growth of a droplet as a function of supersaturation explains well the $\mathrm{CCN}$ activation of water soluble inorganic compounds, but is inadequate in explaining the same in the presence of trace gases and for many organic compounds. Therefore it has been modified to include the effects of surface tension (Shulman et al., 1996; Li et al., 1998; Sorjamaa et al., 2004; Sorjamaa and Laaksonen, 2006), slightly soluble compounds (Shulman et al., 1996; Laaksonen et al., 1998), and condensable trace gases (Laaksonen et al., 1998). However, there are still discrepancies between the theory and measurements when it comes to activation of wettable and insoluble or slightly soluble particles.

Hegg et al. (2001) studied the CCN efficiency of organic aerosols and discovered that with sufficiently long particle growth time, slightly soluble organic aerosols activated in accordance with the model predicted values assuming full solubility. Raymond and Pandis (2002) measured the CCN activity of several organics and compared the results to theoretical values calculated both with traditional and modified Köhler theory. They found significant differences between the experimental and theoretical activation diameters with low solubility organics such as glutamic acid and cholesterol when low solubility and surface tension effects were taken into account. The differences diminished when wettable compounds, that are those whose contact angle with water is zero, were treated as completely soluble. Huff Hartz et al. (2006) gave an explanation for such a behavior. They concluded that some organic particles existed as liquid droplets at very low relative humidities, which would cause erroneous results in

Published by Copernicus Publications on behalf of the European Geosciences Union. 


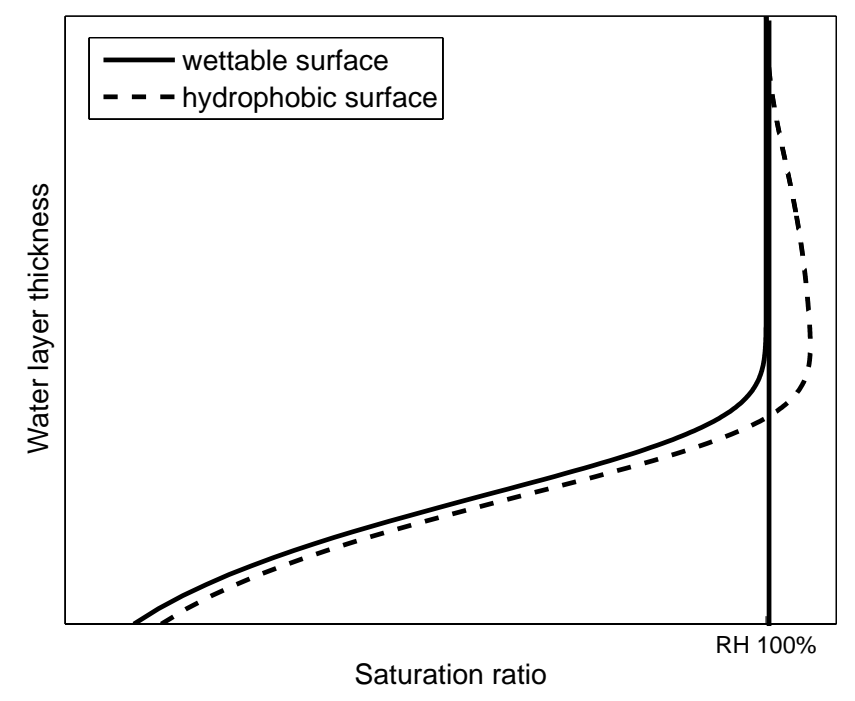

Fig. 1. Schematic adsorption isotherms for wettable (solid line) and hydrophobic (dashed line) surfaces.

CCN studies. This would be because low solubility compounds would act as fully soluble due to insufficient drying of the particles in the diffusion dryer. They also found out that predicted activation diameter is sensitive to small changes in the solution bulk surface tension and that the surface tension in the nanoparticle must be approximately $37 \%$ lower than the surface tension of the bulk solution to gain an agreement between the measured and theoretical activation diameters. This conclusion is, however, contradictory to the results from surfactant partitioning studies (Li et al., 1998; Sorjamaa et al., 2004; Sorjamaa and Laaksonen, 2006) that have shown surface active compounds to partition between droplet surface and interior in such a way that for a given overall solute concentration (total amount of solute divided by total amount of solute plus solvent) the surface tension in fact increases as particle size decreases.

In this paper we suggest an alternative way for wettable organic compounds with very low solubility and/or hygroscopicity to activate as cloud droplets - that is, through multilayer adsorption. Already in the 1960's adsorption was suggested to be a possible cause for particle activation (McDonald, 1964; Jiusto and Kocmond, 1968), but the results from various studies have been somewhat ambiguous and the discrepansies have not been fully explained (Mahata and Alofs, 1975). In our theoretical approach we essentially replace the solute term in Köhler theory by an adsorption isotherm term. As isotherm parameters for water vapor adsorbing on many organic compounds are unknown, we have altered the parameters within reasonable bounds to investigate if adsorption could induce cloud drop activation in atmospheric conditions. The results show that it is possible for adsorption to cause certain types of insoluble particles to activate; however, adsorption measurements for wettable insoluble compounds are required in order to validate this conclusion.

\section{Theory}

Traditionally the cloud activation of insoluble particles has been investigated with the theory of heterogeneous nucleation (e.g. Fletcher, 1958). Heterogeneous nucleation only accounts for adsorption effects in description of the kinetics of water molecule transport to a critical water nucleus on the particle. However, it has also been suggested that cloud activation of insoluble particles could proceed via multilayer adsorption (McDonald, 1964; Jiusto and Kocmond, 1968).

Adsorption depends on properties of the (solid) surface. Consider a perfectly wettable (i.e. zero contact angle) flat surface interacting with water vapor. As relative humidity $(\mathrm{RH})$ is increased, a point is reached where the surface is covered with a monolayer of water molecules. Further increase of RH causes multilayer adsorption, and at $100 \% \mathrm{RH}$ continuous condensation of water vapor follows, which in terms of adsorption means that the number of adsorbed water layers becomes infinite. Figure 1 depicts schematically a multilayer adsorption isotherm, i.e. surface coverage as a function of RH, for a wettable surface (solid line).

Most surfaces, however, are not perfectly wettable: water poured on such surfaces forms spherical caps with nonzero contact angle between the cap and the surface. For continuous condensation of water vapor to take place on a hydrophobic surface (i.e. one with a large contact angle), it is not sufficient to increase the RH to $100 \%$. Figure 1 shows a schematic isotherm (Adamson, 1968) for adsorption on a hydrophobic surface (dashed line): now, the RH must reach some supersaturated value for the continuous condensation to become possible (in practice, this requires that the adsorbed spherical caps fill the surface completely).

Ideally, we would like to study the efficiency of insoluble particles to act as $\mathrm{CCN}$ as a function of the contact angle. This would require an adsorption model connecting the thickness of the adsorbed water layer and the contact angle. Adamson (1968) has in fact presented such model for the purpose of calculating contact angles from adsorption data. Unfortunately, it turns out that the Adamson model does not behave correctly at the limit of zero contact angle. We therefore have to limit our calculations to more traditional adsorption models, which also implies that our results strictly speaking only apply to perfectly wettable insoluble particles.

The adsorbed amount of water can be described with surface coverage $(\Theta)$, that is the adsorbed number of molecules divided by the number of molecules in a monolayer. Surface coverage is in this context calculated as a number of water molecule layers (monolayers) on dry particle surface. The thickness of water layer on top of a solid particle is $\left(D-D_{\text {dry }}\right) / 2$, where $D=$ droplet diameter and $D_{\text {dry }}=$ dry particle diameter. Dividing it by the diameter of a water molecule 
$\left(D_{w}\right)$ gives the surface coverage $\Theta=\left(D-D_{\mathrm{dry}}\right) /\left(2 D_{w}\right)$. Here water molecules are approximated as spherical and intermolecular forces are assumed not to affect the thickness of the water layer.

Model selection in this paper is based above all on practical issues, that is, the amount of data available. There is plenty of adsorption data available for lower saturation ratios and compounds that are not completely wettable but less for high saturation ratios and even less for completely wettable surfaces. The Langmuir isotherm is one of the most wellknown adsorption models, but it only applies to surface coverages up to a monolayer. Isotherms such as BET (Brunauer, Emmet and Teller) and FHH (Frenkel, Halsey and Hill) are probably the most well-known multilayer adsorption models and they were chosen as there was data available to limit the parameter range.

In general, adsorption isotherms can be divided into five types (Brunauer classification, see Adamson and Gast, 1997). Type I characterizes only adsorption up to one monolayer. Types II and III describe multilayer adsorption, and types IV and V capillary condensation in porous solids. Out of the multilayer isotherm types, type III is relatively rare, and we only consider type II isotherms (both BET and FHH belong to this class).

BET isotherm gives the surface coverage as a function of saturation ratio of gas $(S)$ :

$$
\Theta=\frac{c S}{(1-S)(1-S+c S)},
$$

where $c=$ constant related to the heat of adsorption. The BET model is based on the assumption that average heat of adsorption equals the heat of condensation from the second layer upwards. Furthermore, all adsorption sites on the adsorbing surface are assumed equal, each molecule adsorbed in a particular layer is a potential site for adsorption in the next layer, and there are no horizontal interactions between adsorbed molecules. Equation (1) is valid at low pressures, where adsorption is proportional to gas partial pressure.

The idea of FHH isotherm

$$
S=\exp \left(-A / \Theta^{B}\right)
$$

is that the potential field at the surface of a solid decreases with a power of distance. The model is applicable when pressures are close to saturation. The parameter $A$ characterizes interactions between adsorbed molecules and between the surface and adjacent adsorbate molecules (i.e. those in the first monolayer). $B$ characterizes the attraction between the solid surface and the adsorbate in subsequent layers. The smaller the value of $B$, the greater the distance at which the attractive forces act. The values of $A$ and $B$ can be calculated for simplified model potentials (e.g. Van der Waals), but in practice, with real adsorbates and adsorbents, they must be treated as adjustable parameters, and the ranges of their values can only be deduced from experimental data.
The traditional Köhler theory describes the saturation ratio of water vapour over a solution droplet of diameter $D$ to depend on water activity $\left(a_{w}\right)$ and droplet curvature (Kelvin effect)

$S=a_{w} \exp \left(\frac{4 \sigma M_{w}}{R T \rho_{w} D}\right)$

where $\sigma=$ surface tension, $M_{w}=$ molar weight of water, $R=$ universal gas constant, $T=$ temperature, and $\rho_{w}=$ mass density of water. Köhler theory is an equilibrium theory neglecting the droplet growth kinetics. Furthermore, it is valid for soluble compounds, such as inorganic salts, but not for compounds with very low or zero solubility. For such compounds we assume adsorption to be the phenomenon that causes particle to grow. Therefore, by substituting the $a_{w}$ with the $S$ obtained from e.g. the FHH adsorption isotherm, the equilibrium saturation ratio for a solution droplet is obtained from

$S=\exp \left(\frac{4 \sigma M_{w}}{R T \rho_{w} D}\right) \exp \left(-A \Theta^{-B}\right)$.

In general, the FHH isotherm in the above equation can of course be replaced by any desired multilayer adsorption isotherm. (A few days before the submission of this paper it became to our knowledge that B. Henson has presented a similar theoretical idea in a manuscript submitted elsewhere.)

Molecular interactions that would affect monolayer thickness have been disregarded due to lack of explicit data. Furthermore, dry particles are assumed spherical and the effect of surface roughness has not been considered explicitly, although it might affect the results by enhancing adsorption and supressing critical supersaturation (McDonald, 1964; Mahata and Alofs, 1975). However, below we present calculations of the critical supersaturation as a function of the adsorption isotherm parameters, and surface roughness, porosity etc. can be thought of as factors affecting the values of those parameters.

\section{Results}

Because of the scarcity of adsorption data of water vapor on wettable organic surfaces, we explore the behavior of our theory as a function of the FHH parameters $A$ and $B$. As shown by Hill (1949) the FHH model can be derived assuming an idealized system of spherical molecules where the surface interactions on the adsorbed liquid vanish after a few layers, whence the parameter $B$ becomes equal to 3 . In real systems, $B$ is lower. As indicated already by Halsey (1948) and later confirmed by others (see e.g. Carrot and Sing, 1989), $B$ for nitrogen has a value close to 2.7 regardless of substrate material. For other substances, even lower $B$ values have been observed that can also depend on the substrate. Halsey (1948) suggested, based on the data of Boyd and Livingston (1942), that $B$ equals 1 for water vapor adsorption on 


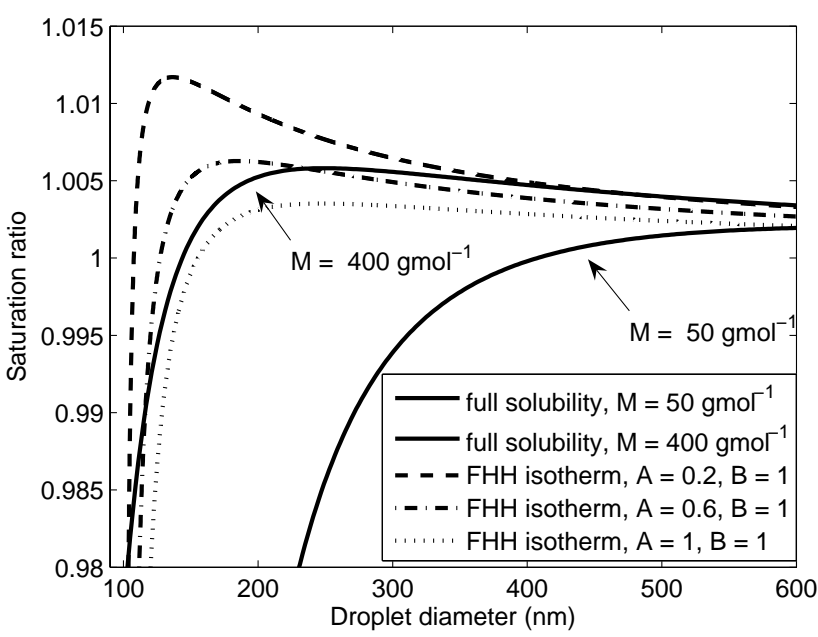

Fig. 2. Köhler curves for a $100 \mathrm{~nm}$ dry particle assuming full solubility (traditional Köhler theory, solid lines) and adsorption (FHH isotherm, broken lines)

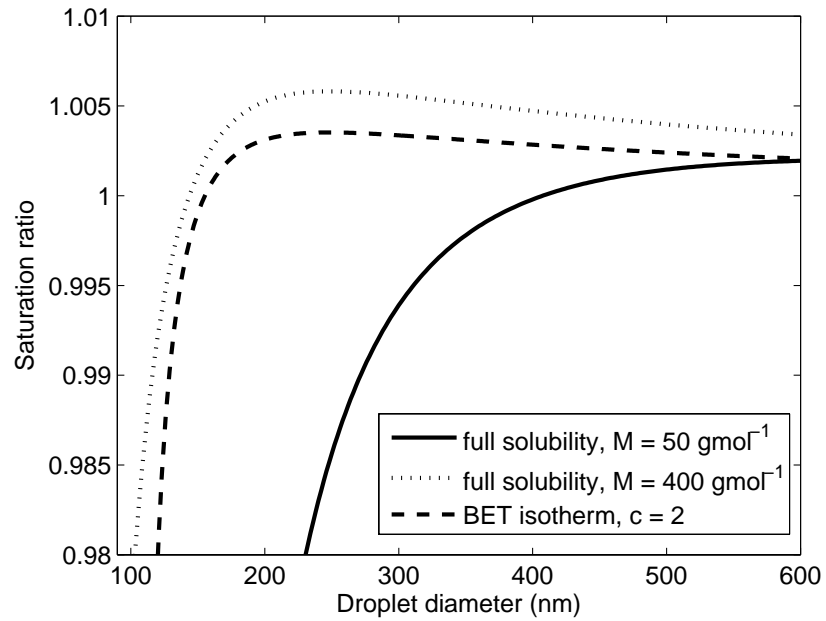

Fig. 3. Köhler curves for a $100 \mathrm{~nm}$ dry particle assuming full solubility (traditional Köhler theory, solid and dotted line) and adsorption (BET isotherm with parameter $c=2$, dashed line)

graphite. Romakkaniemi et al. (2001) studied the adsorption of water on small sodium chloride and ammonium sulphate particles, compounds that are presumably completely wettable due to their high solubilities, and found atypical values for FHH parameters when relative humidity was below the deliquescence point. There is a possibility that the small size of the particles may have affected the parameter values. In any case, they found $B$ values of 0.67 and 0.93 , for sodium chloride and ammonium sulphate, respectively ( $A$ had values of 0.91 and 0.68). Halsey (1948) assumed that $A$ can be taken as unity for practical reasons, while values on the order of 2.5 have been found for notrogen adsorbing on sand

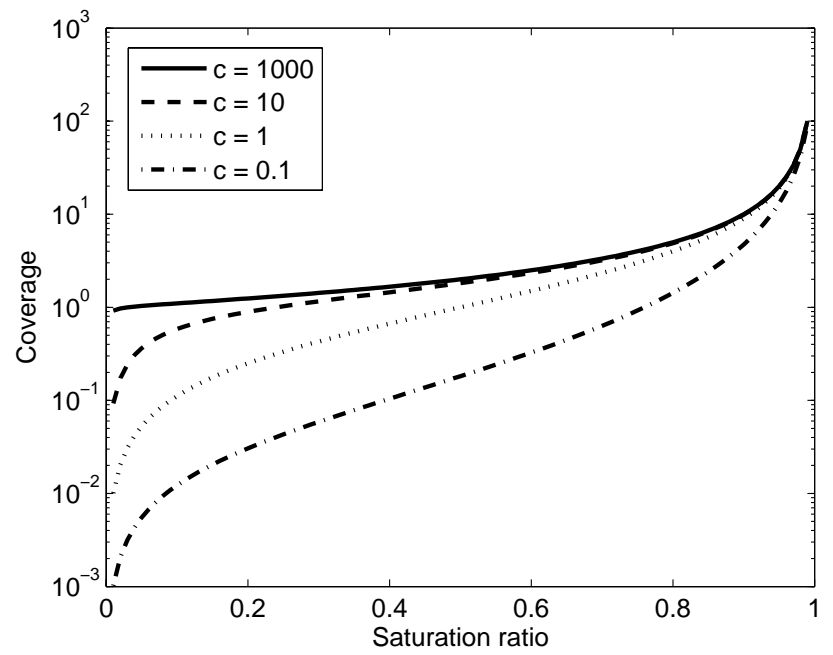

Fig. 4. BET isotherms with four different values of parameter $c$.

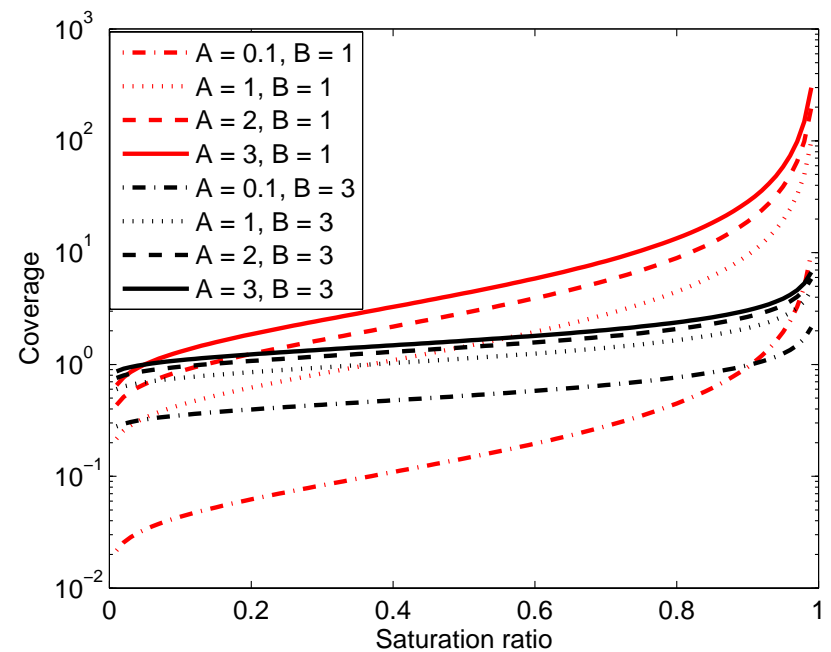

Fig. 5. FHH isotherms with different values of parameters $A$ and $B$.

(Khachikian and Harmon, 2000). Reflecting this span of literature values, we examine the range $0.5<B<3$ below, and $A$ is taken to be between 0.1 and 3 . It is to be noted that the range of parameters chosen for calculations is based on adsorption studies made on inorganic compounds merely because adsorption parameters for organics were not available. Nevertheless, we have no reason to assume the adsorption parameters for organic compounds to differ substantially from those of inorganics.

Figures 2 and 3 present equilibrium growth curves (Köhler curves) for an initially $100 \mathrm{~nm}$ dry particle assuming droplet growth by adsorption. For comparison we also present curves calculated for fully soluble substances with two 
different molar weights, 50 and $400 \mathrm{~g} \mathrm{~mol}^{-1}$ (assuming a density of $1 \mathrm{~g} \mathrm{~cm}^{-3}$, these correspond to molecular volumes of $0.83 \cdot 10^{-28} \mathrm{~m}^{3}$ and $6.64 \cdot 10^{-28} \mathrm{~m}^{3}$, respectively). In Fig. 2 adsorption is described with the FHH isotherm using three sets of parameters as an example. With these parameters the critical supersaturation is comparable with the one calculated for a fully soluble compound with molar weight of $400 \mathrm{~g} \mathrm{~mol}^{-1}$.

Figure 3 shows also the Köhler curves for the fully soluble particles together with an equilibrium adsorption curve calculated with the BET model instead of FHH. The resulting BET curve is in reasonable agreement with the FHH curves of Fig. 2. However, in case of BET, the maximum supersaturation depends very weakly on the value of the parameter c. The reason for this can be seen in Figs. 4 and 5, where we show BET and FHH isotherms at different parameter values. Regarding critical supersaturation, the crucial factor is the behavior of the isotherm at RH's very close to $100 \%$. It can be seen that the BET isotherms become indistinguishable after the water coverage is a few tens of monolayers, whereas the FHH isotherms converge only at much higher coverages. However, it might be that adsorption occurs in a very similar manner for all wettable compounds when relative humidity is close to $100 \%$. As far as we know, there is no experimental data to confirm or deny this. Our results indicate that the FHH distinguishes the adsorption behavior at high RH's on different types of substrates better, and thus we present further calculations for FHH only.

Figure 6 presents curves for critical supersaturation as a function of the parameters $A$ and $B$. As the value of parameter $B$ increases and/or parameter $A$ decreases, the critical saturation ratio required for the droplet to activate increases as well. Broken lines represent the critical saturation ratios for a completely soluble $100 \mathrm{~nm}$ particle again with two different molar weights. It is seen from the figure that when the value of parameter $A$ approaches unity and $B$ diminishes close to unity, the critical saturation ratio for a droplet growing by adsorption becomes reasonable and comparable to those obtained for a completely soluble compound. Thereby, it could be possible for an insoluble wettable compound to activate as a cloud droplet assuming that FHH isotherm parameters close to unity are realistic. In this regard, the assertion of Halsey (1948) that such parameter values apply for water adsorption on graphite is interesting. However, reliable literature data for water vapor adsorption on perfectly wettable organic surfaces is scarce or nonexistant, preventing any firm conclusions at this point.

\section{Conclusions}

The prevailing understanding is that the equilibrium growth of a droplet can be described with traditional Köhler theory or with modified Köhler theory when the compound in question is either water soluble or slightly soluble, respectively.

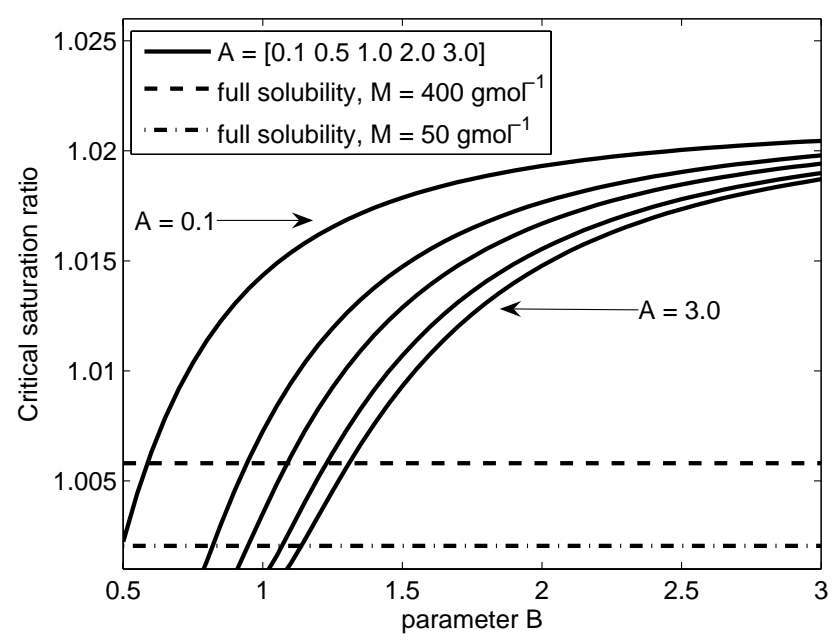

Fig. 6. Critical saturation ratio for a $100 \mathrm{~nm}$ particle as a function of FHH isotherm parameter $B$. Horizontal lines represent the critical supersaturation calculated with traditional Köhler theory assuming full solubility for particles with molar weight of $50 \mathrm{~g} \mathrm{~mol}^{-1}$ and $400 \mathrm{~g} \mathrm{~mol}^{-1}$

These theories generally consider the effect of droplet curvature and the effect of dissolved material that decreases the vapour pressure of water (solute effect). In this paper we have presented a theoretical framework that sheds light on the activation of insoluble wettable particles, a problem that has remained unresolved for decades. The growth and activation of such particles was described by substituting the solute effect in Köhler theory by a term that can be obtained from any multilayer adsorption model. In this work we considered the FHH and BET isotherms, and found that the FHH isotherm is probably more useful from the cloud drop activation viewpoint as it is much more flexible than the BET isotherm at very high relative humidities.

As adsorption data for atmospherically relevant, insoluble, but wettable compounds is scarce, several sets of FHH adsorption parameters were used in calculations of critical saturation ratios. It was found that with certain parameter values the critical saturation ratio of a $100 \mathrm{~nm}$ insoluble particle was close to those of completely soluble particles. Whether or not such FHH parameter values are realistic, however, remains unclear, and is a subject of future study.

Acknowledgements. We thank K. Itkonen for performing initial calculations. This work was supported by the Academy of Finland (through the Center of Excellence program).

Edited by: A. Nenes 


\section{References}

Adamson, A. W.: An adsorption model for contact angle and spreading, J. Colloid and Interface Sci., 27, 180-187, 1968.

Adamson, A. W. and Gast, A. P.: Physical Chemistry of Surfaces, John Wiley \& Sons Inc., 6th edition, 617-618, 1997.

Bilde, M. and Svenningsson, B.: CCN activation of slightly soluble organics: the importance of smalla amounts of salt and particle phase, Tellus, 56B, 128-134, 2004.

Boyd, G. E. and Livingston, H. K.: Adsorption and energy change at crystalline solid surfaces, J. Am. Chem. Soc., 64, 2383-2388, 1942.

Carrot, P. J. M. and Sing, K. S. W.: Adsorption of nitrogen and alkanes by non-porous carbons and silicas, Pure Appl. Chem., 61, 1835-1840, 1989.

Corrigan, C. E. and Novakov, T.: Cloud condensation nucleus activity of organic compounds: a laboratory study, Atmos. Environ., 33, 2661-2668, 1999.

Cruz, C. N. and Pandis, S. N.: A study of the ability of pure secondary organic aerosol to act as cloud condensation nuclei, Atmos. Environ., 31, 22 949-22 958, 1997.

Cruz, C. N. and Pandis, S. N.: The effect of organic coatings on the cloud condensation nuclei activation of inorganic atmospheric aerosol, J. Geophys. Res., 103, 13 111-13 123, 1998.

Fletcher, N. H.: Size effect in heterogeneous nucleation, J. Chem. Phys., 29, 572-576, 1958.

Halsey, G.: Physical adsorption on non-uniform surfaces, J. Chem. Phys., 16, 931-937, 1948.

Hegg, D. A., Gao, D., Hoppel, W., Frick, G., Caffrey, P., Leaitch, W. R., Shantz, N., Ambrusko, J., and Albrechcinski, T.: Laboratory studies of the efficiency of selected organic aerosols as CCN, Atmos. Res., 58, 155-166, 2001.

Hill, T. L.: Physical adsorption and the free volume model for liquids, J. Chem. Phys., 17, 590, 1949.

Huff Hartz, K. E., Tischuk, J. E., Chan, M. N., Chan, C. K., Donahue, N. M., and Pandis, S. N.: Cloud condensation nuclei activation of limited solubility organic aerosol, Atmos. Environ., 40, 605-617, 2006.

IPCC: Climate Change 2001: The scientific basis. Contribution of working group I to the third assessment report of the Intergovernmental Panel on Climate Change, Cambridge University Press, New York, 2001.
Jiusto, J. E. and Kocmond, W. C.: Condensation on nonhygroscopic particles, J. Rech. Atmos., 3, 19-24, 1968.

Khachikian, C. S. and Harmon, T. C.: Effects of nonvolatile organic contamination on the surface areas and adsorption energetics on porous media, Langmuir, 61, 9819-9824, 2000.

Kumar, P. P., Broekhuizen, K., and Abbat, J. P. D.: Organic acids as cloud condensation nuclei: Laboratory studies of higly soluble and insoluble species, Atmos. Chem. Phys., 3, 509-520, 2003, http://www.atmos-chem-phys.net/3/509/2003/.

Laaksonen, A., Korhonen, P., Kulmala, M., and Charlson, R. J.: Modification of the Köhler equation to include soluble trace gases and slightly soluble substances., J. Atmos. Sci., 55, 853862, 1998.

Li, Z., Williams, A. L., and Rood, M. J.: Influence of Soluble Surfactant Properties on the Activation of Aerosol PArticles Containing Inorganic Solute., J. Atmos. Sci., 55, 1859-1866, 1998.

Mahata, P. C. and Alofs, D. J.: Insoluble condensation nuclei: The effect of contact angle, surface roughness and adsorption, J. Atmos. Sci., 32, 116-122, 1975.

McDonald, J. E.: Cloud nucleation on insoluble particle, J. Atmos. Sci., 21, 109-116, 1964.

Raymond, T. M. and Pandis, S. S.: Cloud activation of singlecomponent organic aerosol particles, J. Geophys. Res., 107, doi: 10.1029/2002JD002159, 2002.

Romakkaniemi, S., Hämeri, K., Väkevä, M., and Laaksonen, A.: Adsorption of water on $8-15 \mathrm{~nm} \mathrm{NaCl}$ and $\left(\mathrm{NH}_{4}\right)_{2} \mathrm{SO}_{4}$ aerosols measured using an ultrafine tandem differential mobility analyzer, J. Phys. Chem. A, 105, 8183-8188, 2001.

Shulman, M. L., Jacobson, M. C., Charlson, R. J., Synovec, R. E., and Young, T. E.: Dissolution behavior and surface tension effects of organic compounds in nucleating cloud droplets, Geophys. Res. Lett., 23, 277, 1996.

Sorjamaa, R. and Laaksonen, A.: The influence of surfactant properties on critical supersaturations of cloud condensation nuclei, J. Aerosol Sci., 37, 1730-1736, 2006.

Sorjamaa, R., Svenningsson, B., Raatikainen, T., Henning, S., Bilde, M., and Laaksonen, A.: The role of surfactants in Köhler theory reconsidered, Atmos. Chem. Phys., 4, 2107-2117, 2004, http://www.atmos-chem-phys.net/4/2107/2004/.

VanReken, T. M., Ng, N. L., Flagan, R. C., and Seinfeld, J. H.: Cloud condensation nucleus activation properties of biogenic secondary organic aerosol, J. Geophys. Res., 110, doi:10.1029/ 2004JD005465, 2005. 